Original Research Paper

\title{
Effects of Architectural Irregularities on the Seismic Behavior of Buildings
}

\author{
${ }^{1}$ Sara Mostafa Karra, ${ }^{2}$ Iman Hajal, ${ }^{3}$ Youmn Al Rawi and ${ }^{4}$ Aya Diab \\ ${ }^{1,4}$ Department of Civil Engineering, City U Tripoli, Lebanon \\ ${ }^{2}$ Department of Interior Design, Yanbu University College, KSA, Lebanon \\ ${ }^{3}$ Department of Civil Engineering, Beirut Arab University, Dibbieh BAU Campus, Lebanon
}

Article history

Received: 05-03-2021

Revised: 12-04-2021

Accepted: 16-04-2021

Corresponding Author:

Sara Mostafa Karra

Department of Civil

Engineering, City U Tripoli,

Lebanon

Email: 201410061 @st.cityu.edu.lb
Abstract: Cooperation between the architect and the civil engineer has nowadays become essential in any project for the client's requests' sake. This study was made to show this idea's importance and beneficial consequences. For this purpose, a 40-story dual-system high-rise building has been designed to resist moderate seismic and high wind loads. Three main models were formed: Starting with the net model, which is the regular model, followed by the mass irregularity models that were generated for the luxury floor desires (this irregularity was placed in two different locations, namely at the top and middle position), ending with the soft story irregularity models that were cited in the building's middle and bottom for the gym floor's need. The positions for each irregularity were tested and compared to those of the regular model under the effect of seismic load on one hand and under the influence of three different wind loads on the other. The required wind loads studied in this article were assigned from the wind speeds of 80, 100 and $120 \mathrm{mph}$. For these models' analysis, RSA using finite element method on ETABS was used. The results exhibited that the peak wind speed this building held was $110 \mathrm{mph}$ for both irregularities. Furthermore, the seismically-designed high-rise buildings might not be safe enough to resist a wind load speed of $120 \mathrm{mph}$. In addition, the middle location is the most preferable locus for these irregularities to occur regarding wind and seismic loads because of its minor displacement, drift and base shear. Besides, it ensured the economic cost of the mass irregularity $(\$ 1,706,380)$, which is in turn less than that of the top position $(\$ 1,790,187)$. The same applies for the stiffness irregularity cost, requiring a budget of $\$ 1,632,310$ in the middle position but an expense of $\$ 1,676,368$ for the bottom locus. Although the irregularity's perfect location seemed unfamiliar, it pursues the sake of the client, the architect and the civil engineer alike.

Keywords: Cooperation, Architect, Civil Engineer, High-Rise Building, Regular, Irregular, Mass Irregularity, Stiffness Irregularity, Soft Story, Seismic Load, Wind Load, Dual System

\section{Introduction}

The relationship between Architecture and Civil Engineering is vital for collaborating and directing the safety and quality of any construction. Both jobs have different perceptions, significances and priorities although one's work complete the other's.

Architects play the lead role in accordance with the project's design stage as they are deeply involved in the pre-construction phases. They focus on the building's three-dimensional functionality and aesthetics, including its shape, color and size. Moreover, architects spend the majority of their time creating drawings and plans to be offered to the clients. For this reason, they must have great creativity and vision to attract the latter's attention, all while ensuring that the design complies with their particular region's building codes.

On the other hand, civil engineers deal with a broader series of plans including guiding surveys, analyzing construction sites and materials, calculating cost and 
managing project-related timing, rules and hazards. Their objective lies in producing a safe building considering the aesthetics given by the architect, all while using the lowest budget. Besides, they must be endowed with a critical thinking to solve the problems they might face within various limitations such as the weather variations. Civil engineers divide their time between the office for design purposes and the site to oversee the work's completion.

Architects and civil engineers monitor the construction process to ensure its successful completion. Likewise, they must have the necessary technology skills to generate precise and safe building strategies. They each seek their clients' satisfaction, albeit in different perspectives, leading to arguments between them, especially when it comes to tackling the building's irregularities. When designing buildings in moderate seismic and heavy wind areas, choices made by the architectural designer heavily influences seismic structural performances. In other words, when designing structures having either plan or elevationrelated significant physical discontinuities, they become irregular structures and may lead to complex seismic responses. A frequent plan irregularity arises when any story's seismic weight is more than $200 \%$ of its adjacent story's, which we call mass irregularity, while vertical irregularity often arises from the presence of soft stories, especially located at the ground level or, less frequently, at an intermediate one.

This article discusses the effects of irregularity conditions introduced by architects on a dual-system building's seismic and wind performance, with the goal being not to forbid the designer's intention, but rather to make them aware of their architectural choices' effects. Our current study also sheds the light on the significance of having a flexible relationship between the architect and the civil engineer, where both parties' interests are combined, achieving the architect's requested design beauty at the engineer's lowest cost. It revolves around a residential high-rise building designed against seismic load on one side and wind load on the other. This building was tested on two different irregularities, namely mass irregularity and soft story, in an area where seismic acceleration is of $0.25 \mathrm{~g}$, with different respective wind speed levels of 80, 100 and $120 \mathrm{mph}$. the analysis showed the maximum wind speed this seismically-designed high-rise building could hold, eventually exposing the wind speed at which the building needed its sections to be enlarged. This building was costtested in its normal architectural way and in a new architectural way to assist the importance of the interaction between the architect and the civil engineer. Note that all mentioned abbreviations in this article are listed in Table 1.

\section{Literature Review}

Some articles cannot be ignored, especially when mentioning a building's behavior under seismic load, starting with buildings' behavior in Northern Pakistan during the 2005 Kashmir Earthquake (Naseer et al., 2010) presenting reinforced concrete and masonry buildings' seismic behavior in the northern part of the North-West Frontier Province (NWFP) and Kashmir during the earthquake. Most of the buildings were found to be non-engineered or semi-engineered. Another article followed, discussing the optimal arrangement of energydissipating members for truss structures' seismic retrofitting (Takeuchi et al., 2015). Another article studying the seismic behavior of vertical shear links made of easy-going steel must be essentially mentioned (Daryan et al., 2008). Last but not least, the following paper is of extreme importance as it gives a comprehensive overview about the seismic design of masonry and reinforced concrete infilled frames (Moretti, 2015).

The following articles (Charleson and Pirie, 2009; Türkyılmaz, 2012; El-Gammal et al., 2018; Hurol, 2014; Hazem, 2019) shed light on the importance of the architect-civil engineer collaboration. They stated the difference between both the architect and the civil engineer's points of view towards the building, eventually leading to a failure in their mutual interaction. Reference (Charleson and Pirie, 2009) stated that the civil engineer complains about the architect's lack of structural misunderstanding, while architects are frustrated about the civil engineers' lack of innovation and creativity. Reference (Türkyılmaz, 2012) confirmed that the cooperation between the architect and the civil engineer generates an economical solution that satisfies the architect's constraints and the civil engineer's desire. In ancient civilizations, according to reference (El-Gammal et al., 2018), the responsibilities of both the architect and the civil engineer were combined under one person called the "builder". Due to the revolution of architecture theories and the development of constructions, the presence of two separate persons to receive each a part of the mission was required. They are now recognized as the architect and the civil engineer, respectively. Although both jobs cannot be joined in one person, their respective holders must interrelate as one team to influence a prosperous project. Additionally, should the conflict be between economy and aesthetics, the former will surely lose when the client's budget is not taut (Hurol, 2014). Conversely, when the client's budget is taut, aesthetics and economy fulfillment should be requested. $\mathrm{He}$ suggested to have a team leader with demanding values to solve the struggles between the architects and civil engineers and gather a virtuous teamwork among them. Likewise, reference (Hazem, 2019) defined that collaboration as not about technology to learn, but as a psychology implemented within us. No one can set up codes to fellowship; nevertheless, it only needs passion and willingness to work in groups. As architect EugeneEmmanuel Viollet-le-Duc said in the 1800s, "the interests of the two professions will be best saved by 
their union." It's a fact that civil engineers suffer from the irregularities integrated by the architects in any building's design due to their negative impacts on the building when seismically designed.

The Effect of wind and seismic load has been the focus of attention of many engineers around the world. Many references revolved around this curiosity. Reference (Thilakarathna et al., 2018) specified that high-rise buildings require the study of two major loads, namely the seismic load and the wind load. The article indicated that even though the wind load design level can dominate the seismic load design, seismic load must be carried out to ensure the safety of the building's structural and non-structural components. Another paper, reference (Aly and Abburu, 2015), studied the behavior of two different heights of high-rise buildings (54 and 76 stories respectively) under the seismic and wind load effect. The results showed that high-rise buildings can be affected by high wind loads more than a moderate earthquake. Additionally, reference (El-Shaer, 2014) made a study on the effects of lateral loads prompted from wind and earthquakes on the design of reinforced concrete in high-rise buildings. The analysis covered results of different seismic zones and wind loads on different heights within a building. The wind load is more operative than the seismic load for tall buildings when minimum design factors are considered, whereas an earthquake is established to be more active for short buildings. This reference specified that the wind consequence promptly increases with the height increase. Similarly, reference (Diab and Al-Rawi, 2019) considered the effect of different wind speeds on a seismically-designed high-rise building according to different earthquake-resisting systems for a regular building. Their research consisted of three design cases using three wind velocities and three resisting systems. The results showed that the Shear Wall System (SWS) is one of the preferable systems that can resist seismic load, but it was proven to be the worst system (among those studied) to resist high wind loads. The special moment resisting frame system was proven to be one that can resist both seismic and wind loads, although it required a lot of reinforcement making it economically inadequate. As for the dual system, it was demonstrated to be the most economical system that can resist both seismic and wind loads.

Numerous researches have been conducted, both experimentally and numerically, on the behavior of structures containing irregularities under seismic or wind loads. Reference (Naveen et al., 2019) analyzed the irregular structure's performance under an earthquake load. This study was made on a nine-story building, the structure being modified by incorporating irregularities of various forms in both the plan and elevation to form 34 configurations with a single irregularity and 20 cases with combinations of irregularities. According to the research's results, the vertical geometric irregularity has shown the maximum displacement response. References (Divya et al., 2016), (Hasnat and Rahim, 2013) and (Teddy et al., 2018) investigated the impact of stiffness irregularity in structures. Reference (Divya et al., 2016) studied the impact made by a wind load of $50 \mathrm{mph}$ on 4 buildings. The 4 considered structures were respectively a Regular building, one with irregular Stiffness, a vertical irregular one and a vertical and irregular stiffness building. The results showed that when a Regular building was compared with other Irregular Buildings, the Bending moment and Shear force were less in the former. When the displacement was compared, the Regular building had a higher value than that of the other Irregular buildings. Reference (Hasnat and Rahim, 2013) stated that although the buildings with regular geometry and uniformly-distributed mass and stiffness in plan as well as in elevation suffer much less damage compared to irregular configurations, but the demand created by the latest generation and growing population has nowadays made it inevitable for the architects or engineers to plan irregular configurations, which may lead to serious damage in structural systems. For this purpose, said article studied the response of a 15story frame to lateral loads for stiffness and vertical irregularities. The acquired data showed that the frame's story displacement with a soft story experienced maximum displacement both for wind loads and earthquake loads. However, Reference (Teddy et al., 2018) came from an architectural point of view, giving solutions to reduce soft stories' potency. Several things can be done by architects in their designing processes, such as avoiding direct contact between brick walls, columns and beams, increasing columns' shear capacity by 2.5 times the normal calculation, using shear walls on the first floor, installing bracings and using seismic insulations. Reference (Darshan and Shruthi, 2016) ensured that an irregular structure's behavior to earthquake forces are unpredictable because of the mass irregularity, torsion irregularity, weak story, diaphragm discontinuity, etc. and that the irregularity's effect depends on the used structural model, irregularity location and analysis method; while the Reference (Chethan and Sanjay, 2017) made a comparison between RC buildings' seismic evaluation with and without a mass irregularity. Five models were done for this purpose (mass irregularity for the bottom 5 floors, mass irregularity for the top 5 floors, mass irregularity in even floors, mass irregularity in odd floors and a regular building, respectively). The results showed that the displacement is high in model IV compared to remaining models and is minimum in model $\mathrm{V}$. The story drift is high in model II compared to remaining models and is minimum in model $\mathrm{V}$. Reference (Thilakarathna et al., 2018) stated that wind and earthquake loadings are the two major types of lateral dynamic excitations experienced by high-rise buildings. An efficient design must ensure the safety of a building's structural and non-structural components against both types of loadings. This study evaluated the seismic 
performance of high-rise buildings primarily designed based on different levels of lateral wind loads. A 40story dual-system case study building was selected for this purpose. In dual systems, the lateral load is mainly resisted by a combination of a reinforced concrete core wall and the special moment resisting frame. The case study is separately subjected to wind loading using three different levels of wind speeds (low, moderate and high), which are selected to represent the anticipated hazards at various global wind zones. The detailed seismic performance exhibited by three different design cases (corresponding to different levels of wind hazard) is evaluated. The results showed that the wind load design level can alter high-rise dual-system buildings' seismic performance. Therefore, even for the cases where the wind demands control the design of lateral load-resisting systems, the detailed performance-based seismic evaluation should be carried out to ensure the overall structural safety and integrity. Aly and Abburu (2015) studied the behavior of two different heights of high-rise buildings (54 stories and 76 stories) under multi-hazard loadings. The fundamental differences between wind and earthquake demands were highlighted. The results indicated that earthquake loads excite higher modes that produce lower inter-story drift, compared to wind loads, but higher accelerations that occur for a shorter time. Wind-induced accelerations may have comfort and serviceability concerns, while excessive inter-story drifts can cause safety issues. It also showed that high-rise buildings designed for wind may be safe under moderate earthquake loads as to the main force-resisting system. Lone and Chand (2019) stated that it is a big challenge for tall buildings to withstand the various forces acting from different directions and aspects, such as seismic and wind forces. It also added that it is mandatory when designing a tall building to extremely understand multi-story buildings' seismic and wind behavior. It presented study dealing with the literature review on the behavior of regular and irregular structures' seismic and wind performance by changing the height and terrain category on different structures. The modeling and analysis of the previous structures were studied in light of their shapes and zone. The buildings were modeled and analyzed by the ETABS software using the finite element method that was used in many literature reviews. The Response Spectrum Analysis (RSA) was used for the earthquake's linear analysis in this thesis. It is a plot of the peak or steady-state response (displacement, velocity or acceleration) of a series of oscillators with varying natural frequency that are forced into motion by the same base vibration or shock. The resulting plot can then be used to pick off the response of any linear system, given its natural oscillation frequency. Using the modal response spectrum analysis with the advent of powerful desktop computers, this type of analysis has become the norm. It involves calculating a structure's principal elastic modes of vibration. The maximum responses in each mode are then calculated from a response spectrum then summed by appropriate methods to produce the overall maximum response. Different types of parameters, such as story displacement, story drift, base shear, overturning moment, acceleration and time period, were studied. It has been found that the difference between regular and irregular models gave variation in the displacement and drift due to the lateral forces acting on both building types. Lone and Chand (2019), these conclusions were drawn. The story drift, story displacement, overturning moment, base shear and time period are the important parameters used to analyze and interpret the results; as shape changes, the displacement increases and the lateral load-carrying capacity also changes, meaning that the building's shape plays an important role in the design of the stable structure.

\section{Objectives}

Some articles only focused on the effect of the exerted wind load on the building, while some solely concentrated on the seismic load's effect on the building's behavior. The sections above also paraphrased the articles' studies about the comparison between the wind and seismic loads' effect. However, these studies either focused on the difference in the building's behavior under each load in general cases or on the difference in the behavior for a specific resisting system. Moreover, some articles focused on the consequence of diverse wind speeds and seismic loads on some high-rise regular buildings, while others only studied seismic loads' influence on irregular buildings regardless of wind loads. As for this study, it focuses on six different objectives, namely:

1 Showing the importance of the collaboration between architecture and civil engineering

2 Showing the effect of the architectural irregularities on buildings' seismic and wind behavior

3 Comparing between regular and irregular buildings when designed against earthquakes

4 Comparing between regular and irregular buildings' behavior when designed against wind loads

5 Determining the best locus for the irregularity to assure the interest of the client, architect and civil engineer alike.

6 Making a general determination about the percentage difference between the cost of the different loci

\section{Methodology}

In this study, three models of 40-story high-rise buildings, designed as a dual system facing a seismic acceleration of $0.25 \mathrm{~g}$, were examined and analyzed. The first model was a super regular model that didn't cover any irregularity (Error! Reference source not found. showed the dimensions of this model). The second model resulted as a mass irregularity dual system. The last one had a lateral stiffness irregularity or, in other 
words, a soft-story irregularity dual system. The three models were introduced to three different wind speeds, respectively 80,100 and $120 \mathrm{mph}$. The ultimate wind load held by the seismically-designed high-rise building was discovered and stated for each irregularity. Furthermore, each model was compared to the regular model to accompany the irregularity's best position in accordance with the client's interest, the architect's deign beauty and the civil engineer's expected economic cost and safe building measures. The cost was approximately calculated after the sections' enlargement to ensure the complete safety, even for high wind speeds such as $120 \mathrm{mph}$. In order to accomplish this study, five steps had to be taken:

1 Drawing the seismically-designed five models using the ETABS software, the most popular software used in numerous similar studies, starting from the super regular one that does not contain any irregularity, then introducing the first irregularity (mass irregularity) by doubling the slab thickness and the chosen floor's super imposed dead load to ensure the story's mass is more than 150 percent of its adjacent story's effective mass. For the mass irregularity, two models were drawn, namely the mass irregularity located at top floors and the one located at middle floors. For the other irregularity (Stiffness Irregularity), the same number of models was drawn by increasing columns' lengths so that the chosen floor's lateral stiffness is less than $70 \%$ of that in the story above or less than $80 \%$ of the average stiffness within the three stories above. This irregularity's location was at the bottom and middle floors

2 Computing the results for each model and making relevant seismic comparisons based on the inelastic drift and base shear. Wind comparisons were also done according to the results of story displacements and base shear

3 Determining the maximum wind speed the irregular building can resist (Wind Peak)

4 Enlarging the sections to ensure the irregular buildings' resistance against wind loads of $120 \mathrm{mph}$

5 Estimating the building cost in each model (concrete and steel only), then calculating each cost's percentages increase compared to the regular building, comparing them to each other

\section{Mass Irregularity}

High-rise buildings offer a choice to have an easy access to the ground floor or a great view and a calm atmosphere in the top apartments. Luxury apartments are usually localized in the building's top floors. They require fancy interior styles with their unique wall decor, tiles, lighting and furniture. All the indicated belongings required an increase in the story's effective mass. While designing this building, an extra load was taken into consideration to ensure its safety. The super imposed dead load and the live load were increased at the luxury story level. This loading increase caused slab deflection and cracking problems. For this reason, the slab's thickness was increased to $500 \mathrm{~mm}$. This increase in load and slab thickness in turn increased this story's effective mass by more than $150 \%$ of the adjacent story's. This is why, in this particular case, we faced our first irregularity to be noted in this study: Mass irregularity. Most luxury floors are located at any building's top for the clients to enjoy the beautiful view from the very top. But what about positioning the luxury room in the building's middle, that is to say, at the 20th floor? Isn't that also compatible with the client's and architect's interest? The luxury floor's position was examined in two different ones: At the building's top floor and in the middle at story 20 , respectively. These two positions were examined on a dual system, affected by the three wind speeds revealed above and $0.25 \mathrm{~g}$ of seismic acceleration, the high-rise building to state the position that combines the client's, architect's and civil engineer's interests, in addition to the uppermost wind speed this building could repel.

\section{Soft Story Irregularity}

Due to the population (and thus the overall activity) increase, a 40-story high-rise building was designed to meet up today's demand. The high-rise building compromises floors for several uses, allowing people to carry out their activities in one place. Today's mandates are encircled around the idea of the perfect body image, fitness and health, services which are now being provided by gyms for instance. This high-rise building encompassed a gym floor inspiring people to purchase an apartment in such a building. The reasons behind all that is the unneeded departure, protecting oneself from bad weather, saving time, using one's own bathroom, towels and products to take a shower after one's workout. Architecturally, the gym required an increase in the story height from 3 to $5.2 \mathrm{~m}$ and the addition of a 1.8m-high technical floor directly above it. This height difference led to a lateral stiffness which resulted in a story stiffness. This gym floor is tested and analyzed in two different locations when the building was subjected to wind loads of 80,100 and $120 \mathrm{mph}$ and to a moderate seismic acceleration of $0.25 \mathrm{~g}$. The initial position was in the building's bottom, that is, at the 1st story. However, the next locus is in the middle denoted at the 20th story. Besides, the crowning wind speed was analyzed.

Table 1: Table of Abbreviations

\begin{tabular}{ll}
\hline ETABS & $\begin{array}{l}\text { Extended 3D (Three-Dimensional) } \\
\text { Analysis of Building Systems }\end{array}$ \\
\hline H & Total height of a structure \\
MI & Mass Irregularity \\
MPR & mass participating ratio \\
RC & Reinforced Concrete \\
SI & Stiffness Irregularity \\
UBC & Uniform Building Code \\
\hline
\end{tabular}


Table 2: Regular model dimensions

\begin{tabular}{|c|c|c|c|c|c|}
\hline Number of Stories & 40 & & & & \\
\hline Structure's total height (m) & 120 & & & & \\
\hline Typical story height (m) & 3 & & & & \\
\hline Total floor area $\left(\mathrm{m}^{2}\right)$ & 768 & & & & \\
\hline \multirow{2}{*}{ Columns size $(\mathrm{mm})$} & GF-5 & $6-10$ & $11-20$ & $21-30$ & $31-40$ \\
\hline & 1400 & 1200 & 1000 & 800 & 600 \\
\hline \multirow[t]{2}{*}{ Beams size $(\mathrm{mm})$} & GF-5 & & $6-40$ & & \\
\hline & $900 * 600$ & & $800 * 600$ & & \\
\hline \multirow{2}{*}{ Walls thickness (mm) } & GF-5 & $6-10$ & $11-21$ & $21-40$ & \\
\hline & 500 & 400 & 350 & 300 & \\
\hline Slab thickness (mm) & 300 & & & & \\
\hline
\end{tabular}

\section{Results and Analysis}

After running the analysis on ETABS, the detailed results below were found. The lateral forces acting on the structure (wind and earthquake forces) produced a sway movement on the building resulting alongside its lateral displacement.

\section{Modal Participation Mass Ratio}

In buildings' seismic analysis, if the response spectrum analysis method was used, its accuracy depends on the participating part of the building's total mass in the modal analysis, which is called Mass Participating Ratio (MPR). Most codes, including minimum UBC 97, require a minimum MPR of $90 \%$. In all the models, the MPR exceeds $90 \%$ in the $x$ and $y$ direction.

\section{Drift Verification}

This section analyzed the comparison of MI (top and middle) with the regular model. It also explored SI (middle and bottom)'s evaluation according to the regular model. Figures 1 and 3 showed each model's drift verification paralleled to the regular one.

Figure 1 displayed that the three models (regular model, MI top model and MI middle model), with their particular drifts $(0.01116,0.01218$ and 0.01128$)$, didn't go through the inelastic drift catastrophe because all the models were under the drift limit (0.02) specified by the UBC 97 code. Since the drift graph shown in (Fig. 2) revealed that the regular building's maximum drift is between the middle and top floors (between story 24 and story 28), it would be normal to have a maximum value when the irregularity is located in one of these locations and here the uppermost went to the model having the irregularity in top floors.

\section{Soft Story Irregularity (SI)}

Figure 3 exhibited that the SI models positioned at the bottom and middle $(0.01146$ and 0.01078 respectively) of the building in addition to the regular building (0.01116) didn't show any failure according to the drift based on the UBC limit of 0.02. The highest value here went to the middle irregularity model, which was proved in the section above.

\section{Mass Irregularity (MI)}

\section{Displacement}

Story displacement is the absolute value of a story's displacement under the lateral forces' action. There is a specific limit, according to UBC 97, for a structure's displacement under wind effect that are transcribed in the figures below. This limit is equal to: $\frac{H}{500}$. For MI, the limit is equal to $240 \mathrm{~mm}$, while for SI, the limit is equivalent to $242 \mathrm{~mm}$.

\section{Mass Irregularity (MI)}

Figures 4 to 6 displayed the regular model's displacement with MI (top and middle) according to different wind speeds in the $x$ and $y$ directions respectively. In the $x$ and $y$-direction, the MI models are coincident over each other. The starting displacement was of $122 \mathrm{~mm}$ in the $x$-direction and 60 in the y-direction at a wind speed of $80 \mathrm{mph}$. These displacements increase with the increase of wind speed until they become respectively 273 and $134 \mathrm{~mm}$ in $x$ and $y$ directions at $120 \mathrm{mph}$. However, the regular model slightly surpasses the MI models where it starts with values of $124 \mathrm{~mm}$ and $61 \mathrm{~mm}$ in $x$ and $y$ directions and ends with 279 and $137 \mathrm{~mm}$ respectively. Unfortunately, all of the models exceed the limit $(240 \mathrm{~mm})$ when the wind speed surpasses $110 \mathrm{mph}$ in the $\mathrm{x}$-direction, which exposes the building to a hazardous failure.

\section{Soft Story Irregularity (SI)}

Figure 7 indicated the displacements values of SI and regular models for diverse wind speeds in both $\mathrm{x}$ and $\mathrm{y}$ directions. For both directions, SI middle surpasses both models followed by the regular model and finally the SI bottom model. The regular model starts with a displacement of 124 and $61 \mathrm{~mm}$ in the $x$ and $y$ direction respectively at $80 \mathrm{mph}$; these values were amplified as the wind speed gets stronger until they become respectively $279 \mathrm{~mm}$ and $137 \mathrm{~mm}$ at $120 \mathrm{mph}$. Similarly, the SI middle starts with a displacement of $120 \mathrm{~mm}$ in the $\mathrm{x}$-direction and $63 \mathrm{~mm}$ in the y-direction 
at a wind speed of $80 \mathrm{mph}$, increasing until reaching 288 and $114 \mathrm{~mm}$ respectively at $120 \mathrm{mph}$. Likewise, SI bottom increased from $115 \mathrm{~mm}$ (in the $\mathrm{x}$-direction) and $57 \mathrm{~mm}$ (in the y-direction) at $80 \mathrm{mph}$ to $259 \mathrm{~mm} \mathrm{(x-}$ direction) and $128 \mathrm{~mm}$ (y-direction). Tactlessly, in the $\mathrm{x}$-direction, the models exceed the limit after a wind speed of $110 \mathrm{mph}$ that threatens the building resilience.

\section{Base Shear}

Base shear is an estimate of the maximum expected lateral force that will occur due to seismic ground motion or wind force at a structure's base. The next figures expressed the base shear of each model compared to the regular model.

\section{Mass Irregularity (MI)}

Figure 8 above shows the base shear equality between the systems in every wind speed, as well as the seismic-induced alteration in the base shear between the models. This is due to the calculation way for each load, where the formula of the seismic-induced base shear includes variables that change from one system to the other (the zone factor, the structure's weight, the structural system coefficient and the nearby factor). On the other hand, the base shear formula due to wind load has no variables as it is studied for the same building with the same height, length and wind force. It demonstrated that the model containing mass irregularity at the top held the utmost base shear of $17,404 \mathrm{kN}$ in both $\mathrm{x}$ and $\mathrm{y}$ directions seismic-wise. On the other hand, the base shear produced by MI's middle location is $16,746 \mathrm{kN}$. Now Comparing seismic base shear to that of the varying wind speeds, the base shear generated by a wind load of $120 \mathrm{mph}(18,942 \mathrm{kN})$ surpasses seismic base shear in the $\mathrm{x}$-direction only in addition to the other wind loads. However, the seismic base shear exceeds that of all other wind loads in both directions.

\section{Soft Story Irregularity}

Figure 9 provided an idea about how base shear varied among models. It was shown that the model covering stiffness irregularity at the bottom comprehends the superlative seismic base shear $(17,026 \mathrm{kN}$ in both directions) where the seismic base shear created by the irregularity's middle position is $16,501 \mathrm{kN}$. As mentioned above, the base shear produced by the diverse wind loads matched in both models. Like MI model, the base shear formed by $120 \mathrm{mph}$ has a greater effect than that of the other wind loads and of seismic load in the $\mathrm{x}$ direction only. Nevertheless, the seismic base shear beats all the other wind load base shear.

\section{Summing Up}

\section{Mass Irregularity Summing Up}

For mass irregularity models, we assigned the best section for all models to be adequate for the seismic design, not to mention the fact that there is no conflict with any of the models for the seismic analysis. Now the purpose is to study the different wind speeds' effect on this seismically-designed structure. The results showed in the table above prove that this structure still supported wind up to $110 \mathrm{mph}$ before problems appeared. For all models, the problem was that the displacements exceeded the limits mentioned above for each case. It's known that when this problem is faced, an action should be taken to ensure the structure's safety, but for educational purposes and to know if there is another problem caused by high wind other than the displacement, a checkup was done to study whether the structural elements' design is adequate or not before enlarging it and results showed that all sections were adequate in all these three models.

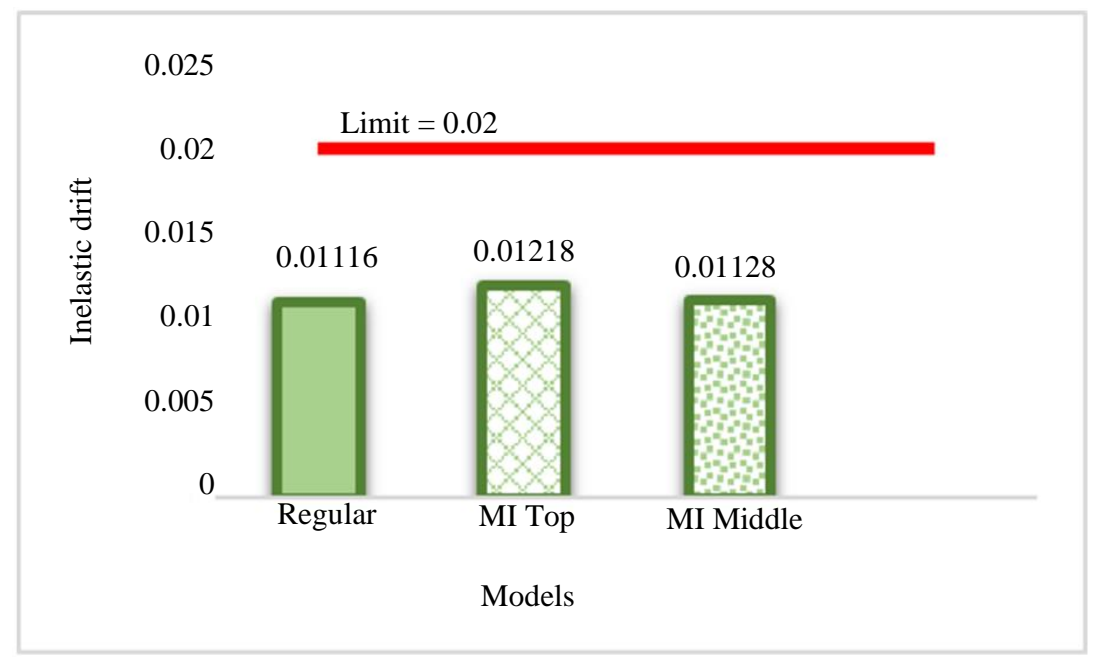

Fig. 1: Inelastic drift comparison between MI models 
Sara Mostafa Karra et al. / American Journal of Engineering and Applied Sciences 2021, 14 (2): 162.176 DOI: 10.3844/ajeassp.2021.162.176

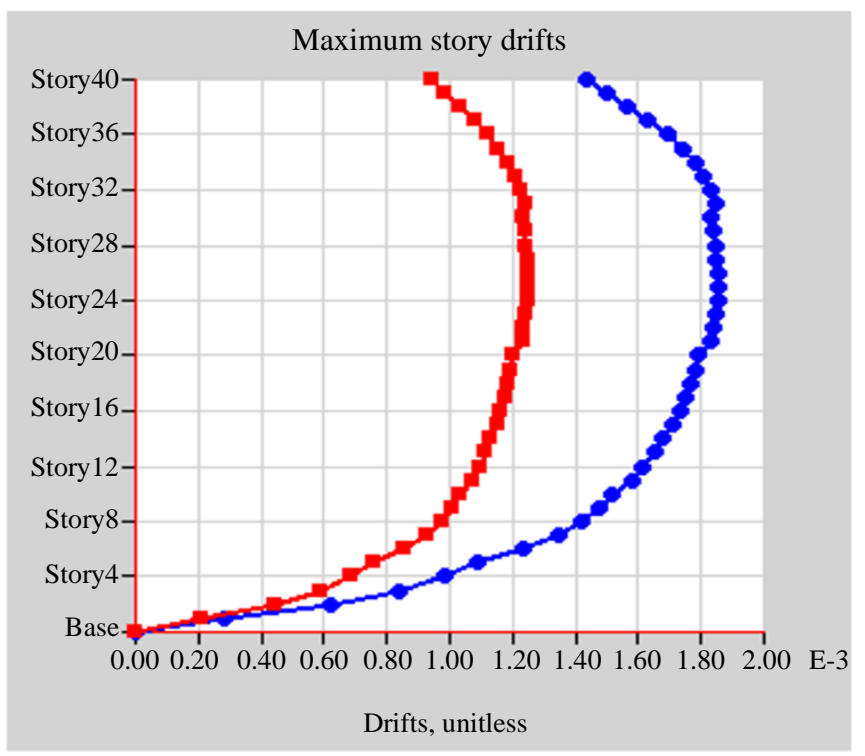

Fig. 2: Story drift for regular model

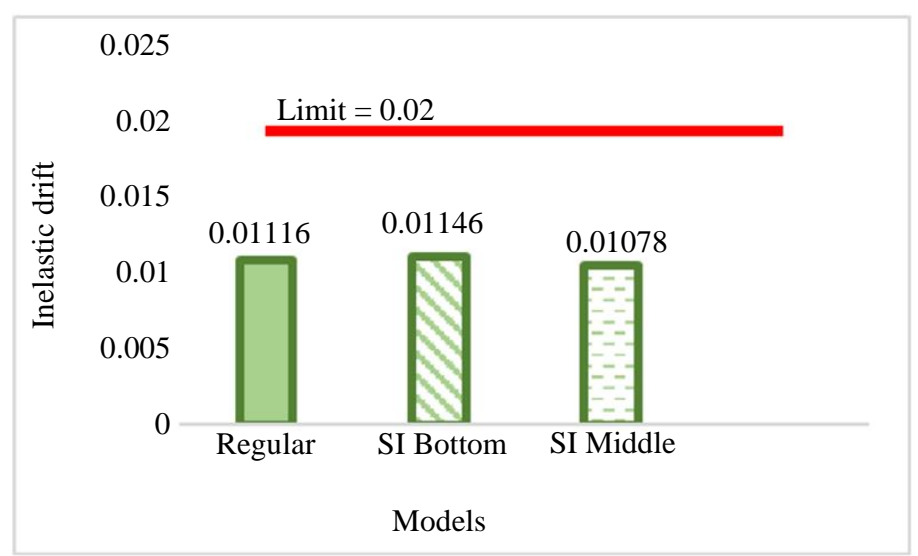

Fig. 3: Inelastic drift comparison between SI models

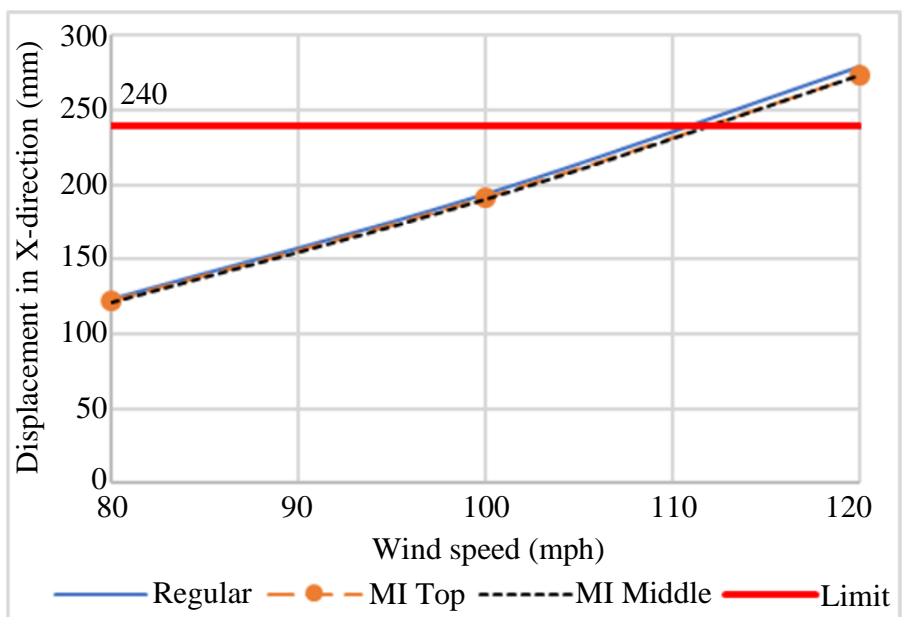

Fig. 4: Comparison between the MI models' displacements in X-direction (mm) 
Sara Mostafa Karra et al. / American Journal of Engineering and Applied Sciences 2021, 14 (2): 162.176 DOI: 10.3844/ajeassp.2021.162.176

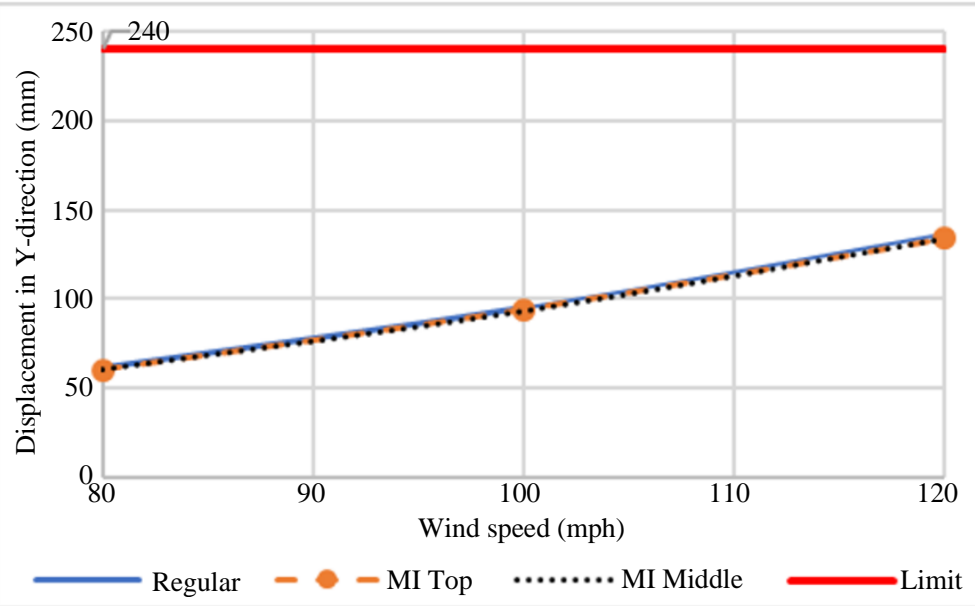

Fig. 5: Comparison between the MI Models Displacements in Y-Direction (mm)

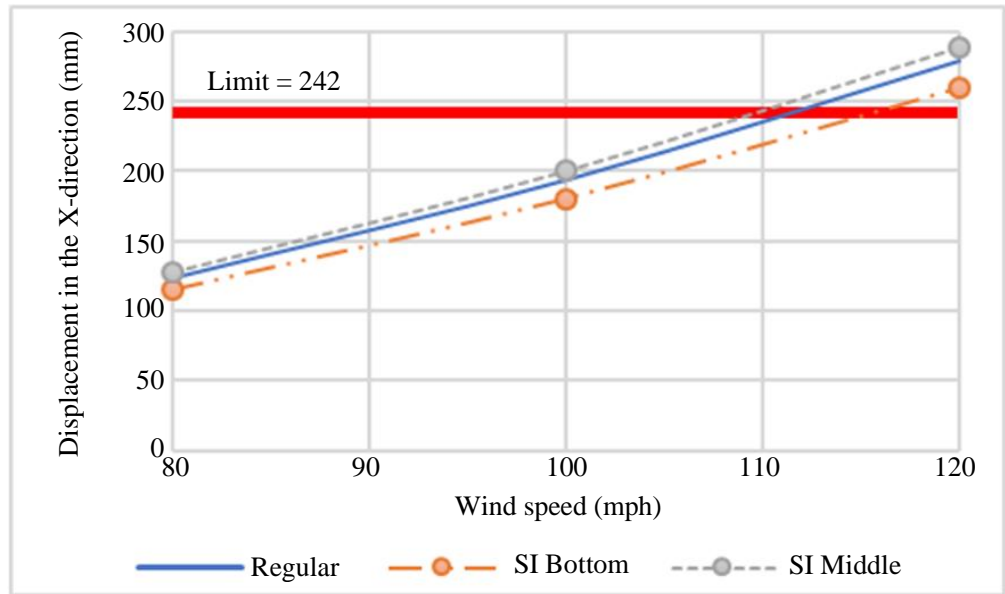

Fig. 6: Comparison between the SI Models' displacements in X-direction (mm)

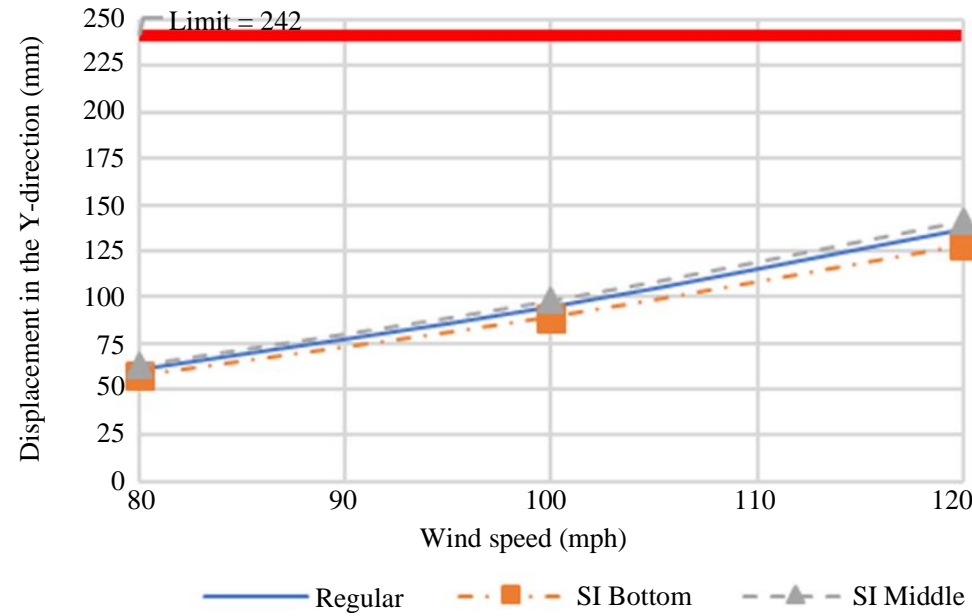

Fig. 7: Comparison between the SI Models' displacements in Y-direction (mm) 


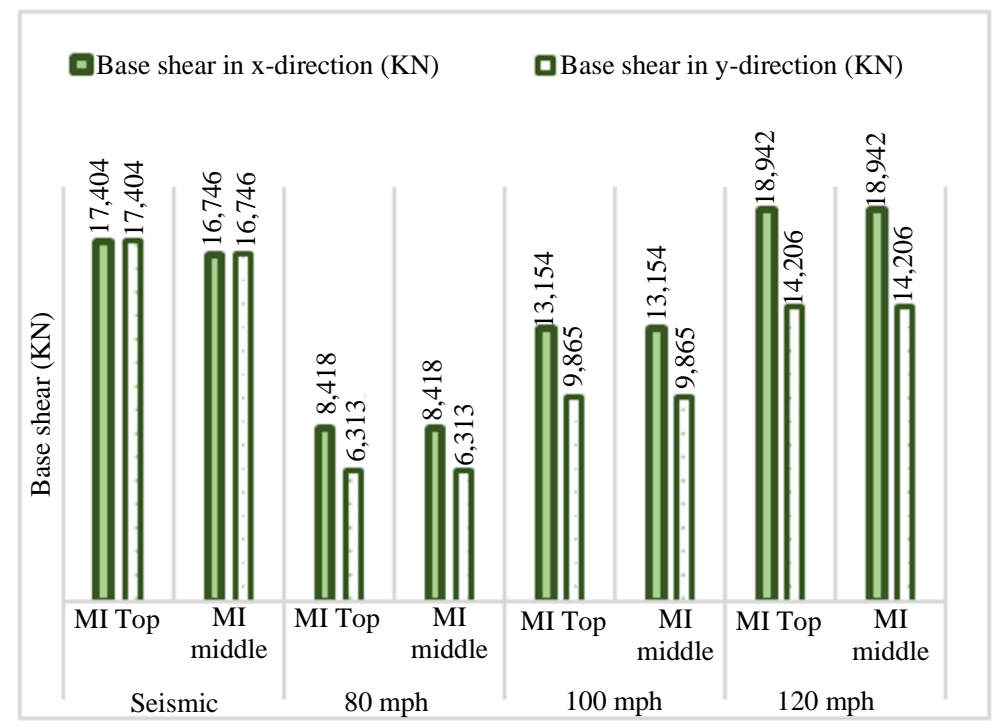

Fig. 8: Base shear comparison between MI models (KN)

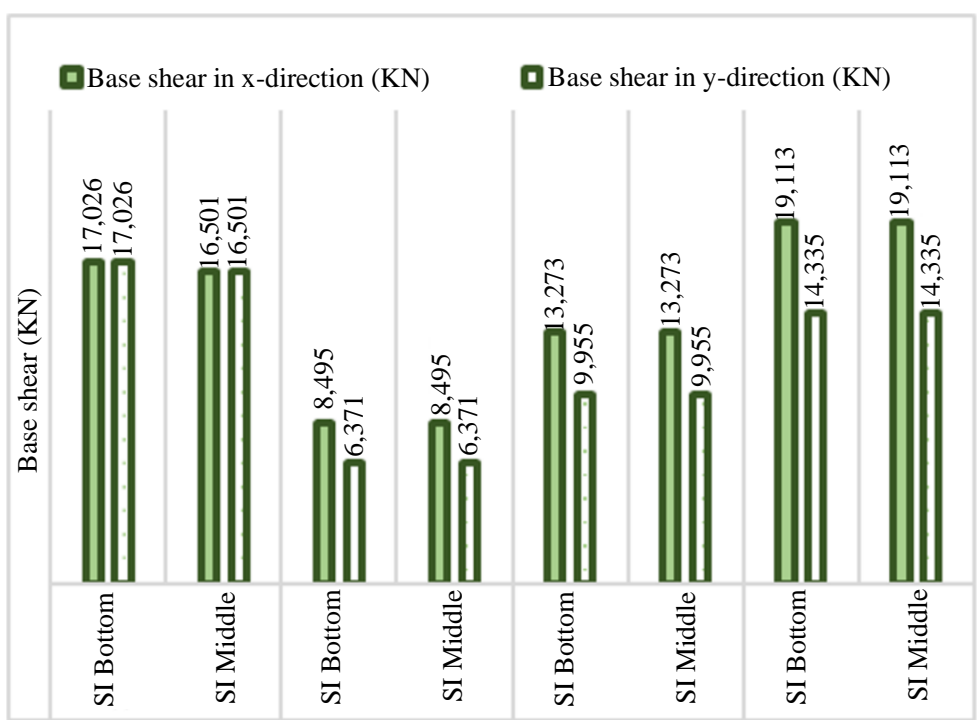

Fig. 9: Base shear comparison between SI models $(\mathrm{KN})$

\section{Stiffness Irregularity Summing UP}

For the stiffness irregularity models, we assigned the best section for all models to be adequate for the seismic design, not to mention the fact that there was no problematic error in any of the models for the seismic analysis. Now the purpose is to study different wind speeds' effect on this seismically-designed structure. The results showed in the table above prove that this structure still supported wind up to $110 \mathrm{mph}$ before problems appear. For the following models (Regular and SI middle), the problem was that the displacements exceeded the limits mentioned above for each case. It's known that when this problem is faced, an action should be taken to ensure the structure's safety, but for educational purposes and to know if there is another problem caused by high wind other than the displacement, a checkup was done to study whether the structural elements' design is adequate or not before enlarging it. Results showed that all sections were adequate in all these two models. On the other hand, for the SI bottom, there was a failure in the shear wall at the bottom floors, in addition to the displacement problems.

\section{Wind Speed's Peak}

The results showed that none of the wind speeds analyzed was the peak wind speed of the irregularity buildings that does not require any amplification in the 
structure's sections. However, one of this article's goals was finding the ultimate wind speed that the building can repel. For this purpose, many wind speed values, localized in the range of 100 to $120 \mathrm{mph}$, were evaluated and tested. All the results pointed out that both irregular models' supreme wind load could resist a speed of 110mph. Any extra speed would guarantee the structure's failure. The most noticeable consequence about these interpreted words was the structure displacement exerted by the 110-mph wind load on both irregularities.

The MI model required a displacement of $231 \mathrm{~mm}$ and $229 \mathrm{~mm}$ in the $\mathrm{x}$-direction with 113 and $115 \mathrm{~mm}$ in the y-direction for MI middle and bottom respectively (Fig. 10). Similarly, the displacement was about to coincide with the building's displacement limit for the SI model having the values of $241 \mathrm{~mm}$ for the $\mathrm{x}$-direction and $118 \mathrm{~mm}$ for the y-direction in both positions as graphed in Fig. 11. This comes as an obvious justification for a wind load of $110 \mathrm{mph}$ being the ultimate wind load that this building, with its altered models, can withstand.

\section{Section Enlargement}

As highlighted in the previous sections, the seismic analysis for all models (the regular one and the irregular ones) exhibited that they can resist the seismic load applied on them without any problem. Similarly, for the wind load analysis, the models didn't show any remarkable difficulty in resisting wind speeds of $80 \mathrm{mph}$ and $100 \mathrm{mph}$, though they exposed a harmless repelling construction. For the regular model, a high wind load of $120 \mathrm{mph}$ didn't express any danger. On the contrary, the high wind load exerted an extra load that the building couldn't handle; this is what happened for instance when surpassing the displacement limit specified in section 4.3 in both irregular models. This leads to the structure bending which consequently ensured the latter's failure.
This structure's purpose was to resist a seismic load with an acceleration of $0.25 \mathrm{~g}$ and wind loads with speeds reaching up to $120 \mathrm{mph}$. for this reason, the section enlargement for each irregular model was a must to avoid the failing catastrophe all while ensuring the architect's interest and needed safety.

The cost, identified in the following section, was calculated and compared after the sections' enlargement to come up with an approximate interpretation about each irregularity model's economical budget regarding its dissimilar locations.

\section{Cost Analysis}

This section gave the approximate concrete and steel cost for each model without going into a deep calculation and computation of the required reinforcement. The cost was based on calculating the volumes for vertical and horizontal elements to get the final volume and expect an approximate cost for each structure. The charge for a concrete with a compressive strength of $60 \mathrm{MPa}$ was 100 $\$ / \mathrm{m} 3$, while the cost for steel was 950\$/ton in Lebanon. The subsequent Tables 3 and 4 showed the cost of each model, monitored by the percent increase of each one according to the regular model presented in Figs. 12 and 13.

\section{Mass Irregularity}

Table 3 contributed an approximate cost for each model that allowed us to compare between models. The comparison showed that the mass irregularity located at middle floors $(\$ 4,071,574)$ was cheaper than the mass irregularity models located at top floors $(\$ 4,299,917)$. Figure 12 also illustrated that the most expensive mass irregularity model was the MI top with a percentage increase of $11.4 \%$ compared to the regular model budget. On the other hand, the mass irregularity located at the middle was more economical than the top locus paralleled to the regular model with a percentage rise of only $5.4 \%$.

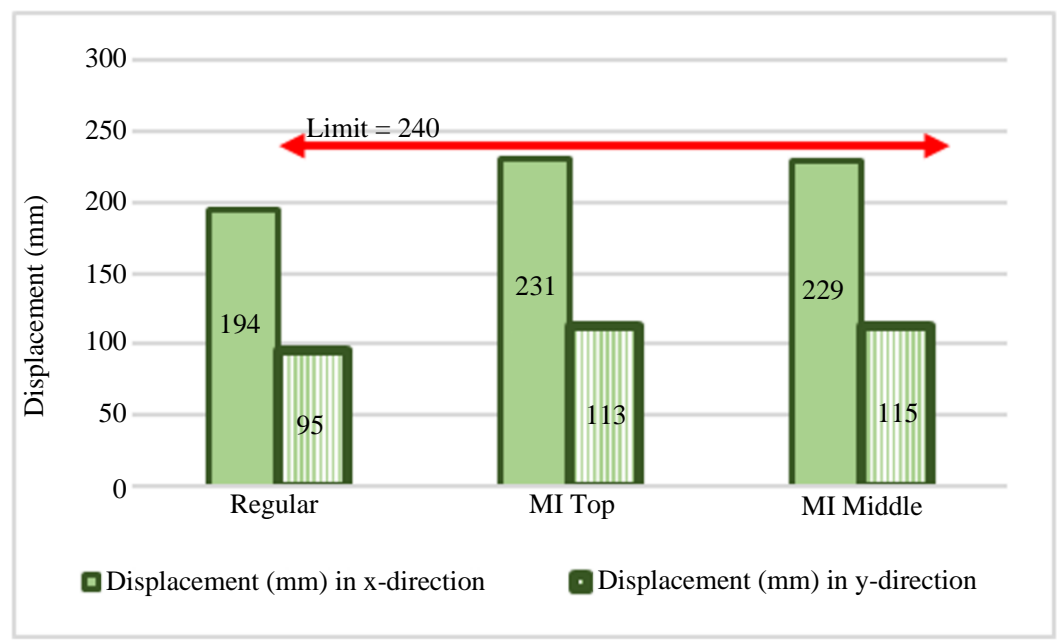

Fig. 10: MI models' displacements under the wind speed $110 \mathrm{mph}$ 
Sara Mostafa Karra et al. / American Journal of Engineering and Applied Sciences 2021, 14 (2): 162.176 DOI: 10.3844/ajeassp.2021.162.176

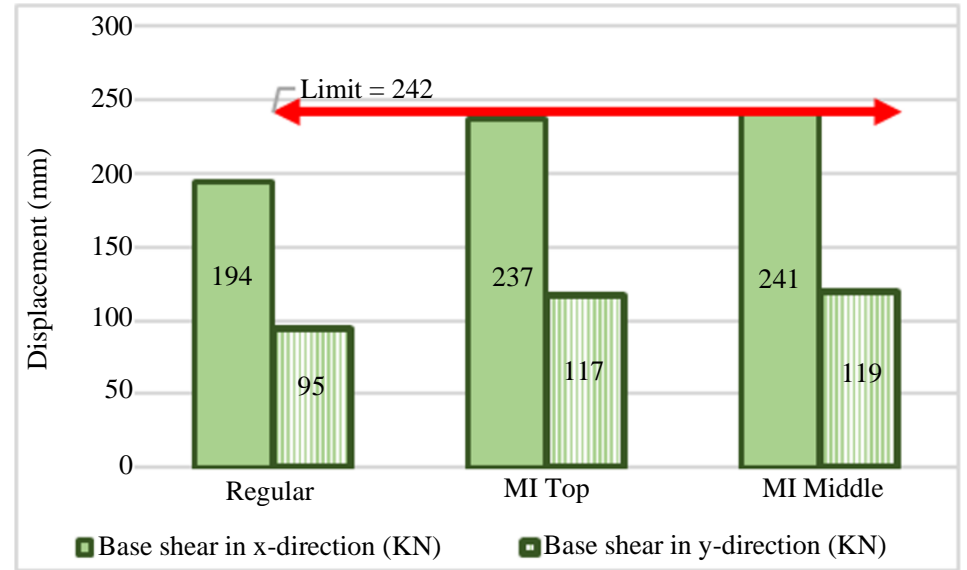

Fig. 11: SI Models' Displacements under the Wind Speed $110 \mathrm{mph}$

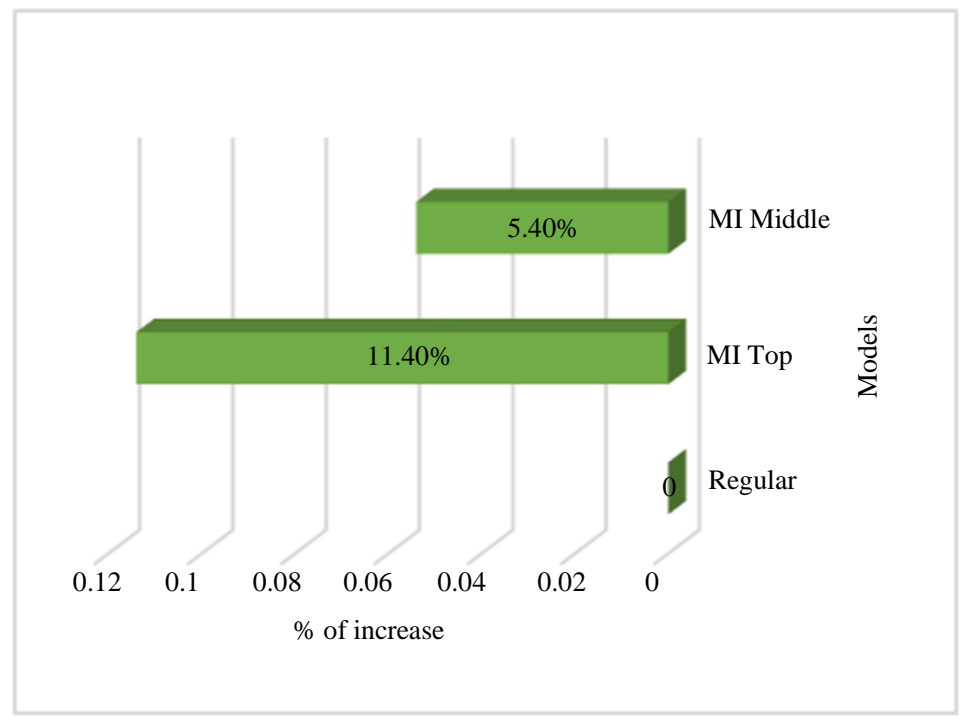

Fig. 12: Increase in cost comparison between MI models (\%)

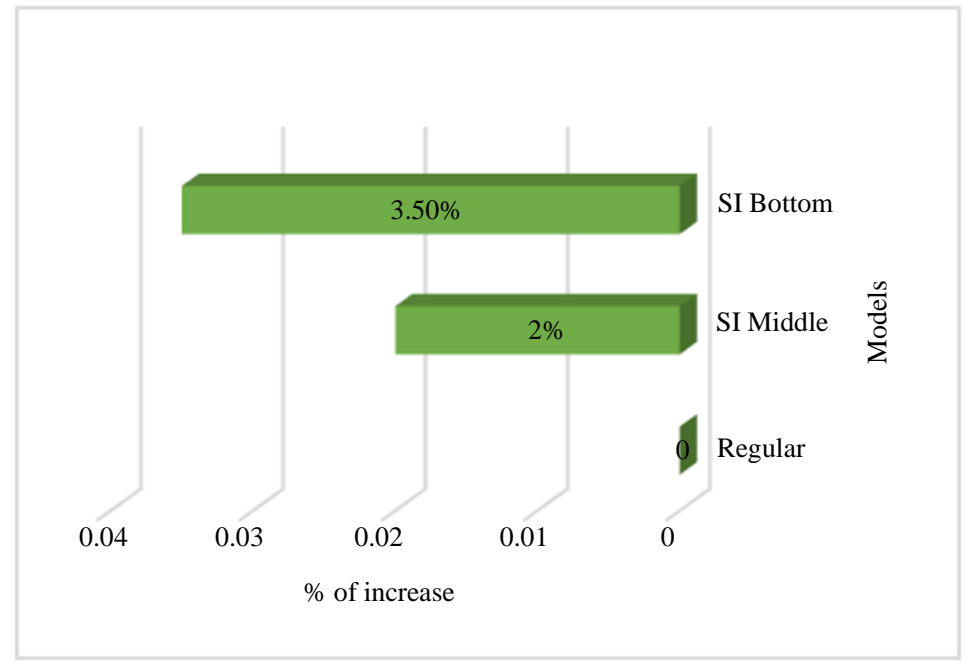

Fig. 13: Increase in cost comparison between SI models (\%) 
Table 3: Cost comparison between MI models

\begin{tabular}{|c|c|c|c|}
\hline & Model & Irregularity location & Cost $(\$)$ \\
\hline \multirow[t]{4}{*}{ Concrete cost } & Regular & ------ & $1,624,200$ \\
\hline & Mass Irregularity & & \\
\hline & $(\mathrm{MI})$ & Top & $1,790,187$ \\
\hline & & middle & $1,706,380$ \\
\hline \multirow[t]{2}{*}{ Steel cost } & Regular & ------- & $2,237,269$ \\
\hline & Mass Irregularity MI & Top & $2,509,730$ \\
\hline \multirow[t]{3}{*}{ Total cost } & Regular & ------- & $3,861,469$ \\
\hline & Mass Irregularity MI & Top & $4,299,917$ \\
\hline & & middle & $4,071,574$ \\
\hline
\end{tabular}

Table 4: Cost comparison between SI models

\begin{tabular}{llll}
\hline & Model & Irregularity location & Cost $(\$)$ \\
\hline Concrete cost & Regular & ----- & $1,624,200$ \\
& Stiffness Irregularity & & \\
& $($ SI) & Middle & $1,632,310$ \\
Steel cost & Regular & bottom & $1,676,368$ \\
& Stiffness Irregularity & ----- & $2,237,269$ \\
& $($ SI) & & Middle \\
Total cost & Regular & bottom & $2,306,467$ \\
& Stiffness Irregularity & ----- & $2,320,880$ \\
& $($ SI) & & $3,861,469$ \\
& & Middle & $3,938,777$ \\
& & bottom & $3,997,248$ \\
\hline
\end{tabular}

\section{Soft Story Irregularity}

For the stiffness irregularity models, Table 4 and Fig. 13 confirmed that mass irregularity's economical position was at the middle floor for its cost $(\$ 3,938,777)$ exceeded the regular model cost $(\$ 3,861,469)$ by slight expenses, namely by approximately $2 \%$. On the other hand, the bottom stiffness irregularity location exceeded the regular model by $3.5 \%$ with an estimated budget of $\$ 3,997,248$.

\section{Discussion}

The paper studied the behavior of a 40-story high-rise building designed according to the dual system. This building was affected by a wind load (of 120mph) and a Seismic load (with an acceleration of $0.25 \mathrm{~g}$ ). It also experienced two irregularities (MI and SI) in two positions.

The subsequent conclusions could be deduced according to the analysis of five different models under different wind load and seismic load conditions:

- Conclusions about the luxury floor (MI models)

- MI top contributed the paramount value for the inelastic drift, supreme displacement and uppermost base shear.
- MI middle provided a cost-effective position for this irregularity paralleled to the top position

- Conclusions about the gym and the technical floor

- The extreme value of inelastic drift, maximum displacement and topmost base shear headed to SI bottom

- SI's economical position was the middle position compared to this irregularity's bottom position

Both irregularities' middle location saved approximately $6 \%$ of the building's general budget concerning the mass irregularity. Similarly, it retained nearly $1.5 \%$ of the project's overall financial plan regarding the stiffness irregularity.

It appeared somewhat weird to have a luxury floor or a gym in the 20th floor instead of locating them in the original spot they used to be in. Conversely, considering this idea from its entire edges, this location ensured the view's attractiveness, responded to the client's demands, the architect's creativeness and the civil engineer's sought safety and economy. This equivalence will not arise except when the civil engineer and the architect work hand in hand to reach any project's peak point. 


\section{Conclusion}

This study's vital specification is that this high-rise building is a total regular building with two irregularities having two altered locations each. As the results displayed and the previous section (section 6) discussed, the most suitable spot for the irregularity in both buildings is the middle position. Although this position seems a little bit weird, it ensures the success of the partnership between the engineer and architect that would result in a high-quality safe building with the most economical financial plan.

Going forward through this study, it has limitations revolving around these irregularities' effect on slabs, beams and foundations. In addition, this study analyzes one specific seismic load acceleration and only two irregularities. These limitations can open the door for many other researches like:

1 Highlighting these irregularities' effect on foundations, beams and slabs

2 Changing seismic load's acceleration and comparing it to wind loads'

3 Testing other irregularities to capitalize the different results that may occur and to highlight the importance of finding each irregularity's suitable position for the sake of accomplishing the concerned individuals' interests in any project

4 Examining the significance of the cooperation between the architect and civil engineer in actual executed projects

\section{Acknowledgement}

Our sincere thanks goes to Faculty of Engineering staff in City University for their kindness, hospitality and technical support.

\section{Author's Contributions}

Sara Karra: She drew the models, did the analysis, computed the results and analyzed it, she displayed the work in a form of research paper.

Iman Hajal: She enriched the project with its excellent architectural information, in addition to her scrutiny of the project from an architectural point of view.

Youmn Al Rawi: She recommended first the idea of collaboration between civil and architectural engineering and she proposed the topic of the research. She supervised this research, helped the engineers in drawing the models and correct them.

Aya Diab: She analyzed the results, calculated the estimated costs and concluded the work, she displayed the work in a form of research paper.

\section{Ethics}

- This material is the authors' own original work, which has not been previously published elsewhere

- The paper is not currently being considered for publication elsewhere

- The paper reflects the authors' own research and analysis in a truthful and complete manner

- All authors have been personally and actively involved in substantial work leading to the paper, and will take public responsibility for its content

\section{References}

Aly, A. M., \&Abburu, S. (2015). On the design of highrise buildings for multihazard: Fundamental differences between wind and earthquake demand. Shock and Vibration, 2015.https://www.hindawi.com/journals/sv/2015/14 8681/

Charleson, A. W., \& Pirie, S. (2009). An investigation of structural engineer-architect collaboration. SESOC Journal, $\quad 22 \quad$ (1), 97. https://search.informit.org/doi/10.3316/INFORMIT. 953777290334543

Chethan, N. B., \& Sanjay, J. S. (2017). Seismic analysis of multistoreyrc building with mass irregularity using etabs. IRJET. - 2017. - p. 8. https://www.irjet.net/archives/V4/i7/IRJETV4I7165.pdf

Darshan, D., \& Shruthi, H. K. (2016). Study on Mas Irregularity of High-Rise Buildings. Int. Res. J. Eng. Technol. (Irjet), 3, 1123-1131.

Daryan, A. S., Bahrampoor, H., Ziaei, M., Golafshar, A., \& Assareh, M. A. (2008). Seismic behavior of vertical shear links made of easy-going steel. American Journal of Engineering and Applied Sciences, 1(4).

Diab, A., \& Al-Rawi, Y. (2019, November). Finite Element Analysis Alteration Between the Effect of Seismic and Diverse Wind Speeds on Three Different Resisting Systems. In International Congress and Exhibition" Sustainable Civil Infrastructures" (pp. 86-97). Springer, Cham. https://link.springer.com/chapter/10.1007/978-3030-34216-6_7

Divya, K., Harsha, S. S., \& Yajdani, S. (2016). Comparitive study on stuructures having vertical and stiffness irregularities under wind load. International Research Journal of Engineering and Technology (IRJET). - 2016. - p. 10. https://www.irjet.net/archives/V3/i8/IRJETV3I8398.pdf 
El-Gammal, Y. O., Ahmad, E. L., \& El-Menshawy, S. (2018). The "Architect-Civil" Working Paradigm. Cur Trends Civil andStruct Eng. 1 (1): 2018. CTCSE. MS. ID, 505.ISSN-10: 2643-6876.

El-Shaer, M. A. (2014). Seismic load analysis of different RC Slab Systems for tall building. ActaTechnicaCorviniensis-Bulletin of Engineering, 7(4), 65.http://acta.fih.upt.ro/pdf/2014-4/ACTA-20144-10.pdf

Hasnat, A., \& Rahim, M. R. I. (2013). Response of building frames with vertical and stiffness irregularity due to lateral loads. International Journal of Engineering Research \& Technology, 2(12).

Hazem, Z. (2019). Architect and Engineer Relationship. https:/www.planradar.com/architect-and-engineerlifetime-conflict/

Hurol, Y. (2014). Ethical considerations for a better collaboration between architects and structural engineers: design of buildings with reinforced concrete frame systems in earthquake zones. Science and Engineering Ethics, 20(2), 597-612. https://link.springer.com/article/10.1007/s11948013-9453-4

Lone, B. A., \& Chand, J. (2019). Comparative Study on Seismic and Wind Performance of Multi-Storeyed Building with Plan and Vertical Irregularities-A Review. International Research Journal of Engineering and Technology, e-ISSN, 2395-0056.

Moretti, M. L. (2015). Seismic design of masonry and reinforced concrete infilled frames: A comprehensive overview. American Journal of Engineering and Applied Sciences, 8 (4), 748.
Naseer, A., Khan, A. N., Hussain, Z., \& Ali, Q. (2010). Observed seismic behavior of buildings in northern Pakistan during the 2005 Kashmir earthquake. Earthquake Spectra, 26(2), 425-449. https://journals.sagepub.com/doi/abs/10.1193/1.3 383119

Naveen, S., Abraham, N. M., \& Kumari, S. A. (2019). Analysis of Irregular Structures under Earthquake Loads. Procedia Structural Integrity. 14,806-819 15. https://www.sciencedirect.com/science/article/pii/S2 452321619301763

Takeuchi, T., Kinouchi, Y., Matsui, R., \& Ogawa, T. (2015). Optimal arrangement of energy-dissipating members for seismic retrofitting of truss structures. American Journal of Engineering and Applied Sciences, 8(4), 455.

Teddy, L., Hardiman, G., Nuroji, \& Tudjono, S. (2018). The Soft Story Challenge to Architectural Design in Earthquake-Prone Areas. Jurnal Kejuruteraan, 30 (2), 141-151. https://core.ac.uk/download/pdf/286377247.pdf

Thilakarathna, S. N., Anwar, N., Norachan, P., \& Naja, F. A. (2018). The effect of wind loads on the seismic performance of tall buildings. Athens Journal of Technology \& Engineering, 5 (3), 251-276.

Türkyılmaz, E. (2012). Collaboration of architects and engineers in structural system configuration through the IdeCAD platform a case study. https://acikerisim.iku.edu.tr/handle/11413/4096 